\title{
The Good, the Bad, and the Talented: Entrepreneurial Talent and Other-Regarding Behavior
}

\author{
Utz Weitzelab \\ Diemo Urbigab \\ Sameeksha Desai ${ }^{\text {c }}$ \\ Zoltan Acs ${ }^{\text {bd }}$ \\ Mark Sanders ${ }^{\mathrm{ab}}$ \\ aUtrecht School of Economics \\ Utrecht University \\ bMax Planck Institute of Economics \\ Jena, Germany \\ 'University of Missouri Kansas City \\ Kansas City, U.S.A. \\ ${ }^{\mathrm{d}}$ George Mason University \\ Fairfax, U.S.A.
}

July 2009

\begin{abstract}
Talent allocation models assume that entrepreneurial talent is selfish and thus allocates into unproductive or even destructive activities if these offer the highest private returns. This paper experimentally analyzes other-regarding preferences of entrepreneurial talent. We find that making a distinction between creative talent and business talent explains systematic differences in other-regarding behavior. Generally, business talent is less willing, and creative talent more willing, to forego private payoffs to avoid losses to others. A moderator analysis reveals that uncreative business talent is significantly less other-regarding than creative business talent, a finding applicable to both certain and risky payoffs with and without negative externalities. The paper makes a contribution to entrepreneurship research by qualifying the implications of talent allocation models and discovering the importance of distinguishing between the two types of entrepreneurial talent. We also add to the field of experimental economics by advancing research on social preferences under risk and with negative externalities.
\end{abstract}

Keywords: development, destructive entrepreneurship, property rights, institutions, poverty trap

JEL classification: D23, L26, O17, 043 and P48

\section{Acknowledgements}

The authors thank David Audretsch, Werner Güth, Erik Monsen, Christian Schade, Erik Stam, the participants of the IPGC workshop (Imperial College in London, May 2009), the researchers of the Strategic Interaction Group at the Max Planck Institute of Economics in Jena (brownbag seminar, June 2008), and the Annual Max Planck Ringberg Conference on Entrepreneurship (Tegernsee, June 2009) for valuable ideas and comments. All remaining errors are ours. 


\section{Introduction}

Traditionally, entrepreneurship is thought to have positive effects on economic growth and welfare. However, since the early 1990s, several theoretical papers have challenged the longstanding notion of the "productive entrepreneur" and stress the importance of building appropriate institutions and incentive schemes to channel entrepreneurial activity. For example, in his seminal paper, Baumol (1990) posits that entrepreneurship is not necessarily productive; it can be just the opposite and can also take unproductive and even destructive forms. He notes that entrepreneurs act in ingenious and creative ways to increase their wealth, power, and prestige and not always with consideration of the effects their activities have on others and/or the economy as a whole. ${ }^{5}$

Essentially, Baumol (1990), Murphy et al. (1991, 1993), Acemoglu (1995), Mehlum et al. (2003), and others argue that entrepreneurial talent allocates into activities "with the highest private returns, which need not have the highest social returns" (Murphy, 1991, p. 506). Most models of talent allocation assume a fixed pool of onedimensional entrepreneurial talent that chooses between productive activities (e.g., starting firms that innovate and foster growth) and unproductive activities (e.g., by redistributing or destroying wealth and reducing growth). ${ }^{6}$ This choice is modeled to depend entirely on private payoffs. In most talent allocation models, incentive systems and institutions determine the private costs and benefits of the different types of activity. Consequently, institutions are seen as completely determining the allocation of entrepreneurial talent. If they reward unproductive activities more than productive activities, entrepreneurial talent chooses the former, despite possible negative externalities for others or adverse effects on economic growth. ${ }^{7}$ Common to talent allocation models, and a central assumption in the literature, is that entrepreneurial talent is not other-regarding (i.e., it is selfish). However, whether people engage in productive versus unproductive entrepreneurial activity depends not only on incentive systems and potential returns, but also on social preferences.

It has long been held in experimental economics that people do have social preferences and that they vary in their degree of other-regarding behavior, variously

\footnotetext{
${ }^{5}$ Here, Baumol (1990) refers to a range of activities that threaten productive entrepreneurship (for related work, see Nunn, 2007; Murphy et al., 1991, 1993; Grossman and Kim, 1995). One example is innovation in rent-seeking procedures, such as "a previously unused legal gambit that is effective in diverting rents to those who are first in exploiting it" (Baumol 1990, p. 897).

${ }^{6}$ Murphy et al. (1993) separate rent-seeking from entrepreneurship by definition. In this paper, we use the broader Baumolian (1990) definition of entrepreneurship that includes rent-seeking activities.

${ }^{7}$ Similar models also offer a more general economic explanation for crime (e.g., Becker, 1968; Ehrlich, 1973) and for violent conflicts (so-called predator-prey models by Hirshleifer, 1987; Bates et al., 2002; Neary, 1997; Skaperdas, 1992).
} 
termed benevolence, altruism, fairness, or inequity aversion. ${ }^{8}$ The overwhelming majority of these studies focus on certain payoffs. Entrepreneurial decisions, however, also involve risk and recently there has been some attempt to investigate the propensity to take a risk when this affects others. Brennan et al. (2008) and Güth et al. (2008) provide first empirical results on this type of "social risk taking." Their major finding is that risk to others appears much less important than own risk, even for those who are otherregarding. Güth et al. (2008) explain this result by suggesting a cognitive "crowding out" of social preferences by own risk. If people are occupied with consideration of their own risky payoffs, they ignore others' well-being, even though they are other-regarding in other situations involving different (i.e., not risky, or not as risky, to themselves) payoffs. In a related study, Bolton and Ockenfels (2008) analyze the effect of social comparison and relative standing on risk taking. Their results suggest that decision makers tend to be more risk averse when their decisions affect others, but less risk averse when the safe option implies an unfair outcome; indeed, unfair outcomes seem to be more acceptable when they are due to chance. Bradler's (2009) results corroborate this, but she finds that other-regarding concerns are not necessarily "crowded out" by own risk, as people prefer fair outcomes even they are costly in the sense of more (or less) risk. In summary, experimental evidence shows, in contrast to the assumptions of most talent allocation models, that social preferences constitute an important element in human decision making, particularly when payoffs are certain, but also under risk.

Although studies in experimental economics have not yet explicitly linked social preferences to entrepreneurial talent, the notion that entrepreneurial talent may be more other-regarding than assumed by Baumol (1990) is widely recognized in the entrepreneurship literature, particularly in the field of social entrepreneurship. For example, Zahra et al. (2009, p.5) define social entrepreneurship as something that "encompasses the activities and processes undertaken to discover, define, and exploit opportunities in order to enhance social wealth by creating new ventures or managing existing organizations in an innovative manner" (emphasis added). Supporting evidence for the importance of social motivations is provided, for example, by Bornstein (2004). Of course, in the field of social entrepreneurship, social preferences play a dominant role, but even in a more general setting, it is prudent to assume that entrepreneurs are at least partially other-regarding. Think, for instance, of the innovative and creative "geek" who invents and promotes a new solution not only for own profit, but to make a positive contribution to the welfare of a country or society at large. Google is well-known example of this type of entrepreneurship, which "considers itself a force for good in the world, even in defiance of commercial logic. Its founders, Larry Page and Sergey Brin, and Eric Schmidt, its chief executive, have said explicitly and repeatedly that their

\footnotetext{
${ }^{8}$ For studies on benevolence or altruism, see, e.g., Trivers (1971), Brennan (1975), Becker (1976), Bester and Güth (1998), and Andreoni and Miller (2002); on fairness or inequity aversion, see, e.g., Bolton (1991), Fehr and Schmidt (1999), and Bolton and Ockenfels (2000).
} 
biggest motivation is not to maximize profits but to improve the world." "Google's founders have chosen "'Don't be evil" as their corporate motto. "They have been mocked endlessly, and understandably, for their corporate motto ..., but probably mean it."

If, based on both experimental economics as well as on the entrepreneurship literature, we accept that other-regarding preferences play a role in human behavior, this can have important policy implications. In general, externalities can create market failures in allocating entrepreneurial talent. Institutions therefore need to internalize these externalities to ensure welfare maximization. If social preferences internalize some of these externalities, then less policy intervention will be needed. It is not a given, however, that social preferences always improve talent allocation. Evidence shows that community standards or fairness can also explain market anomalies with suboptimal resource allocations (Kahneman et al., 1986a, 1986b). Within the pool of entrepreneurs, for example, it is possible that other-regarding preferences allocate the less talented into social entrepreneurship. If social entrepreneurship is considered desirable, it may be necessary to design policy so as to improve the quality of this type of entrepreneurship.

In the more specific context of talent allocation models, social preferences also have policy intervention implications. For example, if entrepreneurial talent is more other-regarding than non-entrepreneurs, the allocative function of formal institutions risks being too restrictive and might even hinder selection of appropriate individuals into productive ventures. If, on the other hand, entrepreneurial talent is negatively correlated with other-regarding preferences, strong formal institutions will be needed to internalize these negative externalities.

The experimental evidence presented in this paper challenges the key assumption that entrepreneurial talent is selfish. Our results stress the importance of distinguishing between different types of entrepreneurial talent, as well as considering the possibility that people do care about inflicting damage on others, even when this damage is not certain. In our experiment, we find that entrepreneurial talent consists of two components: creation (creative talent) and exploitation (business talent). More importantly, however, we find that along these dimensions of entrepreneurial talent people systematically differ in their willingness to forego private payoffs to avoid loss to others. The business-oriented component of entrepreneurial talent is more, whereas the creative component is less, likely to risk collateral damage by engaging in privately profitable unproductive or even destructive activities. These findings and considerations do not change the general conclusion that formal institutions and incentive schemes matter in the allocation of entrepreneurial talent, but they do shed more light on how exactly institutions and incentives function and how they could be improved.

\footnotetext{
${ }^{9}$ The Economist, August 30, 2007a: "Inside the Googleplex." For a similar quote, see The Economist, August 30, 2007b: "Who's afraid of Google?"

${ }^{10}$ The Economist, December 04, 2008: "Enlightenment man."
} 
In this paper, we contribute to the entrepreneurship literature by providing a first experimental analysis linking other-regarding preferences to entrepreneurial talent and by showing the importance of distinguishing between the creative and the business dimensions of that talent. In testing the key assumption of selfish preferences in talent allocation models, we also provide an empirical investigation of the general validity of these models. Furthermore, this paper contributes to the experimental economics literature by studying social preferences and social risk taking with respect to negative externalities, that is, in contrast to most literature in this field, we analyze willingness to risk collateral damage. This is an important contribution because previous work, which mostly does not deal with negative externalities, cannot be generalized to such without a great deal of caution. There are several reasons for this. First, attitudes to risks borne by others have not yet been introduced into economic theory. ${ }^{11}$ Second, there is ample evidence from descriptive decision theory that risk propensity differs with respect to gains and losses (e.g., Tversky and Kahneman, 1992). As most models of talent allocation include risky payoffs with losses for others, there is thus a need for an experimental analysis of social risk taking with negative externalities, which, to the best of our knowledge, this paper is the first to provide.

In Section 2, the different decision tasks (treatments) and the experimental procedures are described in detail. The results of the experiment are reported in Section 3. Section 4 concludes.

\section{The experiment}

\subsection{Decision tasks}

To elicit other-regarding behavior, we rely on six decision tasks (treatments), all based on the dictator game. In fact, Treatment 1 (the base case), is the classic dictator game, where a dictator $d$ receives an amount of money $M$ and then decides on the size of a donation $D \leq M$ to the receiver $r$. In our experiment, $M$ is 10 Euro. The payoff of the dictator, $P_{d}$, and for the receiver, $P_{r}$, are defined as follows: ${ }^{12}$

$$
\begin{aligned}
P_{d} & =M-D, \text { with } 0 \leq D \leq M \\
P_{r} & =D
\end{aligned}
$$

Treatment 1 elicits other-regarding preferences in sure payoffs. Most models of unproductive entrepreneurship, however, involve decisions under risk and distributing sure positive payoffs might involve different behavior than distributing chances for receiving a positive payoff. We therefore modify the classic dictator game to include risky payoffs. Following Karni et al. (2008) and Krawczyk and Lec (2008), we let the

\footnotetext{
${ }^{11}$ In fact, none of the existing theoretical frameworks, neither models of decision making under risk nor models of social preferences, can explain how social preferences of individuals affect decision making under risk (Brennan et al., 2008; Bradler, 2009).

${ }^{12}$ For simplicity, we define the payoffs of all decision tasks as expected monetary payoffs.
} 
dictator decide on how to divide 100 lottery tickets, each of which wins $M$ if drawn. Both the dictator and the receiver have a lottery wheel with 100 lottery tickets out of which one ticket will be drawn. The dictator's lottery wheel contains 100 winning tickets each worth a prize $M$ if drawn; the receiver's lottery wheel contains 100 blanks, each worth zero. The dictator can decide how many of her winning tickets she wants to exchange for blanks of the receiver. This allows a dictator who cares about others to give the receiver a chance to win, too. As shown in the following payoff functions of Treatment 2, the expected payoff for the dictator is thus the probability $p$ of winning the amount $M$, whereas the expected profit for the receiver is based on the complementary probability:

$$
\begin{aligned}
P_{d} & =p \cdot M \\
P_{r} & =(1-p) \cdot M
\end{aligned}
$$

Because risk propensity varies with respect to gains and losses (e.g., Tversky and Kahneman, 1992), we replicate Treatment 2 with a negative prize $M$. This generates the following expected payoffs for Treatment 3:

$$
\begin{aligned}
P_{d} & =-(p \cdot M) \\
P_{r} & =-((1-p) \cdot M)
\end{aligned}
$$

To include negative externalities, we combine the dictator's payoffs in Treatments 2 and 3. In Treatment 4, the dictator does not split the pie of (risky) gains or losses; instead, any increase in the probability of winning $M$ is accompanied by an equally strong increase in the risk of collateral damage (loss for the receiver). In this treatment, both the dictator's and the receiver's lottery wheels each contain 100 blanks. The dictator additionally receives 100 winning tickets each worth $M$, which can be used to convert (draw and replace) blanks in her own lottery. However, every time the dictator converts one of her blanks into a winning ticket, a blank in the receiver's lottery is converted into a ticket "winning" a negative amount, $-M$.

$$
\begin{aligned}
P_{d} & =p \cdot M \\
P_{r} & =-(p \cdot M)
\end{aligned}
$$

In a modification of Treatment 4 , the dictator is able to recover some or all of the negative externalities inflicted on the receiver. In Treatment 5, the chances that the dictator forgoes winning $M$, i.e., $(1-p)$, are used to reduce the risk of collateral damage, i.e., $-(p \cdot M)$. In this treatment, all unused conversions of blanks into winners in the dictator's lottery automatically convert "negative tickets" in the receiver's lottery back into blanks. The dictator is thus able to "neutralize" negative externalities to a sure payoff of zero for the receiver.

$$
\begin{aligned}
P_{d} & =p \cdot M \\
P_{r} & =\left\{\begin{array}{r}
-((p-(1-p)) \cdot M) \\
\text { if } p>0.5 \\
0 \text { if } p \leq 0.5
\end{array}\right.
\end{aligned}
$$


In Treatment 5 , any decision on $p<0.5$ is wasteful. In Treatment 6 , we remove this restriction, so that the dictator can now share positive expected gains by choosing $p<0.5$. That is, once all negative externalities have been neutralized in the receiver's lottery, all of the dictator's remaining unused conversions (up to 100) replace blanks in the receiver's lottery with "positive tickets," each worth $M$ if drawn. The payoffs in Treatment 6 are as follows:

$$
\begin{aligned}
P_{d} & =p \cdot M \\
P_{r} & =-((p-(1-p)) \cdot M)
\end{aligned}
$$

Thus, in Treatment 6 , the dictator can either maximize private revenues by choosing $p=1$, partially or fully neutralize negative externalities by choosing $0.5 \leq$ $p<1$, or share positive expected gains by choosing $p<0.5$.

\subsection{Participants}

Based on the theoretical literature, a pool of entrepreneurially talented people will self-select into a diverse set of available activities. We therefore conducted our experiments with a diverse group of students for whom it is a priori unclear what activities those among them with entrepreneurial talent will select. Despite the potential benefits of focusing on selected professionals for experiments (Alevy et al., 2007; Drehmann et al., 2005; Elston, 2006), there are at least three reasons why established entrepreneurs are not a suitable population for our experiment. First, established entrepreneurs have already made their occupational choice and would therefore bias our sample on one of the possible outcomes of entrepreneurial talent. Second, an experiment with current entrepreneurs would suffer from a survival bias, as survival depends on many things apart from individual talent. Third, it is not the real talent, but the subjectively perceived talent that determines the a priori choice and initial allocation in which are interested. We therefore classify participants according to their subjective perception of their talent to perform activities required to become and be an entrepreneur, i.e., their entrepreneurial self-efficacy.

Three experimental sessions were conducted at the experimental laboratory ELSE at Utrecht University, the Netherlands, in February 2009. Participants were taken from a subject pool of approximately 1,400 registered students of the Utrecht University, which included students all faculties, enrolled in both bachelor and masters programs. Another three sessions were conducted in March 2009 at the experimental laboratory of the Max Planck Institute of Economics, Jena, Germany. There, participants came from a pool of approximately 2,000 registered students of universities located in Jena who were enrolled in bachelor and master-level programs. In both settings, we recruited students from all disciplines, ranging from the natural to the social sciences, with the exception of psychology, students of which were excluded due to their possible previous experience with experiments not following the experimental economics paradigm, which could make 
biased and/or distrustful. Altogether 132 subjects participated, 60 in Utrecht and 72 in Jena. There were 79 male and 53 female participants, with an average age of 22.6 (and a standard deviation of 2.95). Of the 60 dictators (who knew their role in advance), 40 were male and 20 female, with an average age of 22.9 (and a standard deviation of 3.08).

\subsection{Procedures}

Subjects were randomly assigned to pairs and informed of their role in this pair, i.e., receiver or dictator. At no point during the experiment were the students told who the other half of their pair was. ${ }^{13}$ Participants remained in the same pair and played the same role throughout the entire session. The experiment consisted of two sets of treatments. Within each set, presentation of treatments was randomized. In the first set, participants were confronted with the treatments explained in Section 2.1 and in Appendix B. In this set, a few additional treatments (two in Utrecht and three in Jena) of the dictator game with sure outcomes were included. Subsequently, an additional set of 13 treatments, closely related to Brennan et al. (2008) and Güth et al. (2008), was played. These treatments and the additional treatments in the first set are reported and analyzed elsewhere.

Similar to Ben-Ner et al. (2004), who investigate the extent to which personality can affect behavior in dictator games, we included psychometric measurements, especially those related to entrepreneurial self-efficacy, the general "Big Five" personality traits, and some specific measurements on social dominance and responsibility. As described below, these data were used to identify entrepreneurial talent and to run robustness checks where we control for general personality traits. Additionally, each subject answered a few short questions on personal, demographic data.

Both sets of three sessions each followed the same procedure and the sessions were computerized using a program written with z-tree (Fischbacher, 1999). Participants were seated in a random order at PCs, separated from each other by screens. Instructions were distributed before each part of the experiment and questions were answered in private. ${ }^{14}$ All treatments contained a "preview" function, such that participants could proceed only if they pushed the preview button, which resulted in a display of consequences for the dictator as well as for the receiver (see Appendix C). They could push the preview button as often as they wanted, enabling them to better understand the effects of their decisions on the final outcomes. Before starting the experiment, subjects were informed that would receive a 12.50 Euro show-up fee (payable after the experiment); this ensured that no one went home with less money than they arrived with.

\footnotetext{
${ }^{13}$ In Utrecht, the receivers were asked to answer the same question as the dictators but from a hypothetical perspective. In the Jena sessions, 10 dictators were complemented by 14 other players, who were told that they were paired and in one out of seven cases they were the dictator in their pair. Their actual role was revealed at the end of the experiment. In this paper, however, we only focus on the responses of dictators who knew in advance that they were dictators.

${ }^{14}$ Upon request, the instructions are available from the corresponding author.
} 
Earnings in the experiment were determined by one individually and randomly selected treatment per pair. This led to an average payoff of about 15 Euro per subject, but with substantial variance between 2.5 and 27.5 Euro. The duration of the experiment was about 90 minutes.

\subsection{Psychometric measurements}

Entrepreneurial self-efficacy has been measured at different levels of relatedness to entrepreneurship: Wilson et al. (2007) at a more general level, Zhao et al. (2005) at a more specific level. ${ }^{15}$ We utilize Wilson et al. (six items), extend it with items from Zhao et al. (2005), and add two items at the specific level suggested by Erik Monsen in a personal communication (see Appendix A). ${ }^{16}$ To validate the internal structure, we run a common factor analysis. The common factor analysis yields three factors with eigenvalues above 1; the third just marginally exceeds 1 . The three factors relate to creativity, to general self-efficacy, mainly based on Wilson's items, and more specific self-efficacy based on the Zhao and Monsen items. When factorizing without the creativity items, there is only one factor with an eigenvalue exceeding 1. Also Velicer's (1976) Minimum Average Partial (MAP) test, which is less susceptible to overestimating the number of factors, suggests only two factors. We therefore separate the creativity items from the rest of the items to form the creativity factor $C$ (two items, $\alpha=0.76$ ), while the other items form the (entrepreneurial) business talent factor BT (10 items, $\alpha=$ $0.79)$. $^{17}$

In addition to entrepreneurial self-efficacy, we administered the Social Dominance Scale (Sidanius and Pratto, 1999), which involves preference for hierarchy, discrimination, and domination within any given social system, and the Social Responsibility Scale (Berkowitz and Lutterman, 1968); both scales are considered to elicit behavior toward others as well as social preferences. The social responsibility items form a one-dimensional scale (a common factor analysis results in a single factor with an eigenvalue above 1) and the internal reliability measured by Cronbach's alpha is 0.55 . A factor common analysis for social dominance yields two factors with eigenvalues above 1 , one factor for positively and one for negatively framed items. According to Spector et al. (1997), this may well represent an artificial factor structure and we thus consider it, too, as one-dimensional. The corresponding Cronbach's alpha is 0.91 .

\footnotetext{
${ }^{15}$ Chen et al. (1998) measure entrepreneurial self-efficacy at a very specific level, including, for example, the perceived ability to set and meet market-share goals. However, this scale was specifically designed to distinguish entrepreneurial from managerial self-efficacy, but not from other backgrounds. Analogous to our argument for excluding real entrepreneurs, we therefore consider this scale inappropriate for our purposes.

${ }^{16}$ As a robustness check, we also tested the scales without the two items suggested by Erik Monsen. The results were qualitatively unchanged from those reported here.

${ }^{17}$ This factor includes one item with weak loadings, i.e., the ability to manage money.
} 
We also integrated a 10-item short version of the "Big Five" personality traits, which describe five broad psychological factors or dimensions of personality. These factors have been found not only to be related to entrepreneurship (Zhao et al., forthcoming), but also to explain behavior in dictator games (Ben-Ner et al., 2004). The scale developed by Rammstedt and John (2007) includes two items for each of the following dimensions: extraversion (larger score reflects more outgoing and sociable personality), agreeableness (larger score reflects more trusting and less suspicion toward others), conscientiousness (larger score reflects more self-discipline, duty consciousness, and achievement orientation), neuroticism, sometimes called emotional stability (larger score reflects a personality that is emotionally reactive and vulnerable to stress), and openness (larger score reflects an imaginative rather than a down-to-earth, conventional personality). A common factor analysis extracting five factors based on an oblique rotation leads to the expected loadings above 0.4 on their corresponding factors, but below 0.22 on other factors. Due to the extreme shortness (two items), reliability coefficients (Cronbach's alpha) vary substantially and are on average rather low, 0.73, $0.39,0.46,0.67$, and 0.39 . Only extraversion and neuroticism show acceptable levels of internal reliability. We nevertheless keep all variables in the analysis but treat the results with caution.

\section{Experimental results}

In the following analysis, we focus on a subset of responses, i.e., on the 60 dictators who knew in advance that they were dictators. The different versions of the dictator game that we employ are difficult to compare as they require participants to respond in different ways, e.g., give away sure Euro amounts or convert lottery tickets. However, all versions of the game share the characteristic that the dictator can give negatively valued objects away, take positively valued objects from the other, or generate positively valued objects for her own or the other's benefit. The effect on the partner is completely determined once the dictator makes a choice. Furthermore, the two extreme responses are the same in all treatments; either the dictator receives nothing or gives away everything with certainty, or the dictator receives 10 Euro or does not lose 10 Euro with certainty. The treatments only differ with respect to interior results. Regardless of the game's structure, the dictator can continuously vary her own expected payoff between 0 and 10 Euro or between -10 and 0 Euro. To simplify analysis and reporting of results, we transform all responses such that they are normalized between 0 and 10 and describe the amounts as the "good thing" the dictator keeps, takes, or generates for herself. Thus, not losing is considered a "good thing"; we refer to this as keeping. We further calculate a combined response by standardizing (calculating the z-scores for) each treatment and calculating the sum over all treatments. This cumulated response does not describe the

average keeping, but it describes the overall relative deviation from the population mean 
and therefore describes how much a participant deviates on average from the mean. The standardization controls for the fact that in different treatments, the variance can differ.

Table 1

Table 1 reports correlations of psychometric variables and combined response. Within the set of dictators, both creativity and business talent are virtually independent ( $\rho$ $=-0.01$ with $\mathrm{p}=0.96$; see Figure 1). Creativity, as well as business talent, correlate with extraversion, but creativity correlates positively with openness and business talent correlates negatively with neuroticism. Note further that the cumulated response correlates negatively with creativity and positively with business talent. Similarly, neuroticism is negatively correlated with the cumulated response, but extraversion and openness are not.

Figure 1

For responses to all treatments, as well as for the combined response, Table 2 reports the means, standard deviation, median, and nonparametric correlation tests (Spearman and Kendall's tau) of keeping with business talent and creativity. Although the correlations are not always significant, the overall pattern suggests that business talent is positively correlated with keeping more for oneself, whereas creativity seems to be negatively correlated in this regard. However, correlation analysis cannot reveal whether or not business talent and creativity interact. We therefore inspect the data visually (see Figure 2).

Figure 2

We split the sample into four roughly equal-sized subgroups (via median splits along the two dimensions, creativity and business talent): $\mathrm{BT}+/ \mathrm{C}+, \mathrm{BT}+/ \mathrm{C}-, \mathrm{BT}-/ \mathrm{C}+$, and $\mathrm{BT}-/ \mathrm{C}-$. When plotting the average response for each of the four groups (see Figure 2 ), one group stands out - those who consider themselves as talented in business but less creative.

Table 2

To investigate whether this visual result is statistically valid, we test the following conditions nonparametrically: (1) BT $+/ \mathrm{C}-$ is larger than the remaining three groups, (2) 
the remaining three groups are alike, (3) BT $+/ \mathrm{C}-$ differs from each of the remaining three groups, and (4) all four groups together are not alike (see Table 3). Results reveal that these conditions almost always hold true; there are just two exceptions. In Treatment 8 , $\mathrm{BT}+/ \mathrm{C}-$ does not differ significantly from BT-/C-; in Treatment 5 , the test as to whether all four subgroups are from the same population is not significant. However, all signs of binary comparisons are as predicted. There is a small tendency for the creative but not business talented, i.e., BT-/C+, to be more similar to the business talented but uncreative, i.e., $\mathrm{BT}+/ \mathrm{C}-$, than to the other two subgroups. We therefore tested whether this group differs from the other two subgroups within these three remaining subgroups; we find no significance at all. The overall evidence therefore suggests that the general pattern shown in Figure 2 holds across all treatments (see Figure 3 for treatment-specific plots equivalent to Figure 2).

Table 3

The nonparametric tests conducted to this point were based on an artificial dichotomization at the median, which is appropriate because in many treatments the responses are bimodal. However, by dichotomization we lose information. To analyze the dependencies in more detail we also employ an ordered probit regression analysis. We selected the ordered probit because people might anchor on specific points for their decisions instead of considering the whole spectrum of possible responses. They might, for instance, focus on values that can be divided by 10 . We report robust standard errors based on seemingly unrelated estimations (Weesie, 1999). The model for the combined response is estimated independently. As control variables we include age, gender, and the city where the data were collected. Table 4 summarizes the regression results. Note that our conclusions do not change if we employ an ordinary least square regression (estimation results are not reported here) instead of the ordered probit regression.

Table 4

Table 4 shows that participants in Jena tend to keep more for themselves, that creative people tend to keep less and business-talented participants tend to keep more, and that there is a negative interaction between both effects, such that those who are creative and business talented do not keep as much for themselves as those who are not creative but still business talented. Results from the nonparametric analyses are therefore confirmed based on parametric regression controlling for some basic demographic variables.

Although the distinct behavior of the uncreative but business-talented people is more or less robust across the different treatments, one could suspect that participants' 
behaviors are basically the same across all treatment and that they simply did not care about variations in the different treatments. Spearman's rank correlation coefficients between responses are between 0.69 and 0.87 , indicating a rather close relation between responses to different treatments, but a median comparison based on the Wilcoxon signed-rank test indicates that the absolute levels of responses vary significantly between treatments. For instance, in T4, where a dictator cannot neutralize losses caused to the receiver, participants keep significantly less for themselves compared to T6 and T7, where they can neutralize such losses $(\mathrm{p}<0.05)$. In fact, out of 15 binary comparisons, eight differences are significant at the $0.5 \%$ level, three at the $5 \%$ level, and four are insignificant (T5 vs. T6, T1 vs. T5 and T6, and T2 vs. T3). The latter clearly form groups of treatments: T5 and T6 are treatments where the receiver's losses can be neutralized and $\mathrm{T} 2$ and $\mathrm{T} 3$ are treatments that do not mix gains and losses. These level differences between treatments allow us to conclude that treatments do indeed make a difference (manipulation check). Additionally, that we observed the same pattern for uncreative but business-talented people across all treatments is strong support that this particular finding is robust.

To more technically test the robustness of our results, we include additional variables such as social dominance, social responsibility, and the "Big Five" personality traits. We run this analysis for the combined response only (see Table 5). Model VIII in Table 5 reports a regression without our model variables. Social dominance is not significant, but social responsibility and neuroticism are. The relation between social responsibility and behavior in dictator games is obvious; the relation between neuroticism and dictator games is less so. When including our model variables and the Big Five personality traits (Model V), we observe that the coefficient of openness changes substantially, which indicates a potential multicollinearity problem. Indeed, openness and creativity are substantially correlated $(\mathrm{r}=0.65$; see Table 1$)$. The coefficient of business talent also changes by approximately 20 percent, which is not surprising as neuroticism and business talent are correlated, too. When excluding the corresponding dimension of the Big Five, creativity (Model VI) and business talent (Model VII) become significant (see Models VI and VII). Note that independent of these multicollinearity issues, for all models the interaction between creativity and business talent remains significant, again indicating the robustness of our finding.

Table 5 


\section{Discussion and conclusions}

\subsection{Summary}

This study sought an answer to the question of whether the entrepreneurially talented care about other people or, instead, act to maximize their own payoffs. More specifically, we were interested in whether entrepreneurial talent selects into actions that hurt other people. We find that social preferences and avoiding negative externalities on others are systematically related to entrepreneurial talent. Interestingly, however, this finding is not uniform across the two types of talent considered essential to entrepreneurship, i.e., creativity and the ability to start and run a business. These two dimensions reveal an interesting interplay. One group of participants, those who consider themselves to have business talent but not be especially creative, stands out from the rest: this group keeps comparatively more and cares comparatively less about others. While this seems to support Baumol's (1990) assumption as to the profit-maximizing behavior of entrepreneurial talent, that assumption does not hold true for creative people. The group of creative people who also have business talent does not care less but, instead, cares significantly more about others than do those who are uncreative but talented in business.

\subsection{Limitations}

Our study is not without limitations. We used tested and published psychometric scales to measure entrepreneurial self-efficacy. In validating them, however, we found that they represent two distinct factors, creativity and business talent, which factors were then used in our further analysis. There are many studies on entrepreneurial self-efficacy, but we could find only a single study arguing that creativity needs to be psychometrically distinguished from entrepreneurial business talent. In recent research in career development, based on an survey of 1,847 Israeli working adults, Danziger et al. (2008) report that within Schein's career anchor inventory, which is a set of questions aimed at identifying fundamental preferences regarding one's career, the "entrepreneurial creativity" dimension needs to be split into two factors: entrepreneurship and creativity. These results, along with our own findings, clearly demonstrate that more research is needed to improve the rather rudimentary measurement of creativity vis-à-vis other business-related talents.

Our study of losses is limited by the fact that the participants could not actually lose money in the experiment due to the high show-up fee. Our design therefore potentially suffers from the aggregation effect, where participants net the show-up fee with the payoffs, rather than considering the show-up fee as a lump-sum windfall gain. Feedback from participants after the experiment, however, indicated that low payoffs were felt as losses from the initial endowment. We therefore believe that the endowment

effect is more dominant than the aggregation effect. The aggregation effect is probably 
also mitigated by the fact that participants generally expect to earn about 10 Euros per hour and so earning a positive but lower amount is viewed as an opportunity loss.

Despite randomizing participants from a wide range of disciplines, students with business-related majors might be correlated with specific personality traits and behavior. As a robustness check we therefore dummied all participants with majors in business, management, or economics (12 in Utrecht; 9 in Jena). Unreported regression analyses show that these participants do not behave differently from others.

The higher internal validity of laboratory research is often seen as the price paid for lower external validity. To mitigate the latter, we took great care to include a set of diverse treatments that all are related to the dictator game, but incorporate very different characteristics. The fact that we find treatment effects in absolute levels of responses indicates that treatments do indeed make a difference. However, the fact that entrepreneurial talent behaves qualitatively similarly across all treatments makes us confident that the results generalize to other contexts as well. Note that our findings are especially significant for the games where the dictator can increase her chances of gain while at the same time increasing the receiver's chance of a negative payoff. We believe that this version of the dictator game shows particular potential for further investigation in a wider context.

\subsection{Implications}

Entrepreneurial behavior is complex. Experiment-based investigation of it tends to focus on very specific aspects, e.g., risk taking in investment decisions or market entry decisions (Camerer and Lovallo, 1999; Elston et al., 2006). This study contributes to this body of research by investigating the other-regarding preferences of entrepreneurial talent. The treatments used in this paper that incorporate risk and negative externalities proved to be a suitable experimental design, especially for capturing central elements of entrepreneurial decision making that go beyond market entry and risk taking.

We derive two main implications from our findings on other-regarding preferences of entrepreneurially talented people that may inform future research. First, entrepreneurial talent is at least two-dimensional with respect to its effects. Our results clearly show that business talent needs to be distinguished from creativity. Wilson et al. (2007) and Zhao et al. (2005), along with others in the empirical entrepreneurship literature, combine both dimensions. For some research questions, however, not disentangling these two dimensions of talent may produce misleading results.

Second, and more importantly, our findings challenge existing theories on the allocation of entrepreneurial talent. We demonstrate that other-regarding behavior is correlated with entrepreneurial talent, more specifically, with certain structural components of talent, such that the allocation of entrepreneurial talent does not depend 
only on incentive systems and formal institutions, but also on social preferences. Allocation models need to take this into account.

Our findings that creativity needs to be distinguished from business talent and that uncreative business talent is less other-regarding than creative business talent suggest an interesting path for theory development. We suggest that creativity is linked with value or rent creation, whereas business talent is linked with rent appropriation. While it is widely accepted that entrepreneurs need both (which is why measures of entrepreneurial selfefficacy include both), people whose talent is differently focused might allocate into different types of opportunities. This may explain our finding that creative business talent is less maximizing with regard to own profits. Creative business talent may focus more on appropriating the rents they create themselves instead of considering rent seeking as an alternative. The less creative, however, may anticipate that they themselves will create less value and are thus inclined to rely more on appropriating rents from others. As a consequence, uncreative business talent could select relatively more into opportunities that maximize their profits while creative business talent balances rent seeking with rent creation. 


\section{References}

Acemoglu, D. (1995) Reward Structures and the Allocation of Talent. European Economic Review 39: 17-33.

Alevy, J. E., Haigh, M. S., List, J. A. (2007) Information Cascades: Evidence from a Field Experiment with Financial Market Professionals. Journal of Finance 62(1): $151-180$.

Andreoni, J., Miller, J. (2002) Giving According to GARP: An Experimental Test of the Consistency of Preferences for Altruism. Econometrica 70: 737-753.

Bates, R., Greif, A., Singh, S. (2002) Organizing Violence. Journal of Conflict Resolution 46(5): 599-628.

Baumol, W. (1990) Entrepreneurship: Productive, Unproductive and Destructive. Journal of Political Economy 98: 893-921.

Becker, G. (1968). Crime and Punishment: An Economic Approach. Journal of Political Economy (76): 169-217.

Becker, G. (1976) Altruism, Egoism, and Genetic Fitness: Economics and Sociobiology. Journal of Economic Literature 14(3): 817-826.

Ben-Ner, A., Putterman, L., Kong, F., Magan, D. (2004) Reciprocity in a Two-Part Dictator Game. Journal of Economic Behavior \& Organization 53: 333-352.

Berkowitz, L., Lutterman, K. (1968) The Traditional Socially Responsible Personality. Public Opinion Quarterly 32: 169-185.

Bester, H., Güth, W. (1998) Is Altruism Evolutionary Stable? Journal of Economic Behavior and Organization 34: 193-209.

Bolton, G. (1991) A Comparative Model of Bargaining: Theory and Evidence. American Economic Review 81(5): 1096-1136.

Bolton, G., Ockenfels, A. (2000) ERC: A Theory of Equity, Reciprocity and Competition. American Economic Review 90: 166-193.

Bolton, G., Ockenfels, A. (2008) Risk Taking and Social Comparison-A Comment on Betrayal Aversion: Evidence from Brazil, China, Oman, Switzerland, Turkey, and the United States. Working Paper Series in Economics, University of Cologne.

Bornstein, D. (2004) How to Change the World: Social Entrepreneurs and the Power of New Ideas. Oxford, UK: Oxford University Press.

Bradler, C. (2009) Social Preferences Under Risk-An Experimental Analysis, Jena Economic Research Papers, 2009-022.

Brennan, G. (1975) Pareto Desirable Redistribution: A Perspective. Finanzarchiv 33: 234-271.

Brennan, G., Güth, W., Gonzalez, L., Levati, M. V. (2008) Attitudes Toward Private and Collective Risks in Individual and Strategic Choice Situations. Journal of Economic Behavior and Organization 67, 253-262.

Camerer, C., Lovallo, D. (1999) Overconfidence and Excess Entry: An Experimental Approach. American Economic Review 89(1): 306-318.

Chen, C. C., Greene, P., Gene Crick, A. (1998) Does Entrepreneurial Self-Efficacy Distinguish Entrepreneurs from Managers. Journal of Business Venturing 13(4): 295-316.

Danziger, N., Rachman-Moore, D., Valency, R. (2008) The Construct Validity of Schein's Career Anchors Orientation Inventory. Career Development International 13(1): 7-19. 
Drehmann, M., Oechssler, J., Roider, A. (2005) Herding and Contrarian Behavior in Financial Markets-An Internet Experiment. American Economic Review 95: $1403-1426$

Ehrlich, I. (1973) Participation in Illegitimate Activities: A Theoretical and Empirical Investigation. Journal of Political Economy LXXXI: 521-565.

Elston, J., Harrison, G., Rutström, E. (2006, May) Experimental Economics, Entrepreneurs and the Entry Decision. Mimeo.

Hirshleifer, J. (1987) The Economic Approach to Conflict. New York: Paragon House Publishers, 335-364.

Fehr, E., Schmidt, K. (1999) A Theory of Fairness, Competition, and Cooperation. Quarterly Journal of Economics 114(3): 817-868.

Fischbacher, U. (1999) z-Tree. Toolbox for Readymade Economic Experiments. IEW Working Paper 21, University of Zurich.

Grossman, H., Kim, M. (1995) Swords or Ploughshares? A Theory of the Security of Claims to Property. Journal of Political Economy 103: 1275-1289.

Güth, W., V. Levati, Ploner, M. (2008) On the Social Dimension of Time and Risk Preferences: An Experimental Study. Economic Inquiry 46(2): 261-272.

Kahneman, D., Knetsch, J. K., Thaler, R. (1986a) Fairness as a Constraint on Profit Seeking: Entitlements in the Market. American Economic Review 76(4): 728741.

Kahneman, D., Knetsch, J. K., Thaler, R. (1986b) Fairness and the Assumptions of Economics. Journal of Business 59(4): 285-300.

Karni, E., Salmon, T., Sopher, B. (2008) Individual Sense of Fairness: An Experimental Study. Experimental Economics 11(2): 174-189.

Krawczyk, M., Lec, F. L. (2008) Social Decisions Under Risk. Evidence from the Probabilistic Dictator Game. Mimeo.

Mehlum, H., Moene, K., Torvik, R. (2003) Predator or Prey? Parasitic Enterprises in Economic Development. European Economic Review 47: 275-294.

Murphy, K., Shleifer, A., Vishny, R. (1991) The Allocation of Talent: Implications for Growth. Quarterly Journal of Economics 106: 503-530.

Murphy, K., Shleifer, A., Vishny, R. (1993) Why is Rent-Seeking So Costly to Growth? American Economic Review 83: 409-414.

Neary, H. (1997). Equilibrium Structure in an Economic Model of Conflict. Economic Inquiry (35): 480-494.

Nunn, N (2007) Historical Legacies: A Model Linking Africa's Past to its Current Underdevelopment. Journal of Development Economics 83: 157-175.

Rammstedt, B., John, O. P. (2007) Measuring Personality in One Minute or Less: A 10Item Short Version of the Big Five Inventory in English and German. Journal of Research in Personality 41: 203-212

Sidanius, J., Pratto, F. (1999) Social Dominance: An Intergroup Theory of Social Hierarchy and Oppression. Cambridge, New York, Melbourne: Cambridge University Press.

Skaperdas, S. (1992) Cooperation, Conflict, and Power in the Absence of Property Rights. American Economic Review (82): 720-739.

Spector, P. E., Van Katwyk, P. T., Brannik, M. T., Chen, P. J. (1997) When Two Factors Don't Reflect Two Constructs: How Item Characteristics Can Produce Artifactual Constructs. Journal of Management 23(5): 659-677. 
The Economist (2007a) Inside the Googleplex, August 30.

The Economist (2007b) Who's Afraid of Google? August 30.

The Economist (2008) Enlightenment Man, December 04.

Trivers, R. (1971) The Evolution of Reciprocal Altruism. Quarterly Review of Biology 46: 35-57.

Tversky, A., Kahneman, D. (1992) Advances in Prospect Theory: Cumulative Representation of Uncertainty. Journal of Risk and Uncertainty 5: 297-323.

Velicer, W. F. (1976) Determining the Number of Components from the Matrix of Partial Correlations. Psychometrika 41: 321-327.

Weesie, J. (1999) Seemingly Unrelated Estimation and the Cluster-Adjusted Sandwich Estimator. Stata Technical Bulletin 52: 34-47.

Wilson, F., Kickul J., Marlino D. (2007) Gender, Entrepreneurial Self-Efficacy, and Entrepreneurial Career Intentions: Implications for Entrepreneurship Education. Entrepreneurship: Theory \& Practice 31(3): 387-406.

Zahra, S. A., Gedajlovic E., Neubaum D. O., Shulman J. M. (2009) A Typology of Social Entrepreneurs: Motives, Search Processes and Ethical Challenges. Journal of Business Venturing, doi: 10.1016/j.jbusvent.2008.04.007

Zhao, H., Seibert S. E., Hills G. (2005) The Mediating Role of Self-Efficacy in the Development of Entrepreneurial Intentions. Journal of Applied Psychology 90(6): 1265-1272.

Zhao, H., Seibert, S. E., Lumpkin, G. T. (forthcoming) The Relationship of Personality to Entrepreneurial Intentions and Performance: A Meta-Analytic Review. Journal of Management. 


\section{Appendix A.}

\section{Items for measuring entrepreneurial self-efficacy}

\begin{tabular}{|c|c|c|}
\hline & Items & Source \\
\hline \multicolumn{3}{|c|}{$\begin{array}{l}\text { How do you compare yourself to fellow students in your } \\
\text { ability to ... }\end{array}$} \\
\hline a) & ... solve problems? & Wilson et al. (2007) \\
\hline b) & ... manage money? & Wilson et al. (2007) \\
\hline c) & ... be creative? & Wilson et al. (2007) \\
\hline d) & ... get people to agree with you? & Wilson et al. (2007) \\
\hline e) & ... be a leader? & Wilson et al. (2007) \\
\hline f) & ... make decisions? & Wilson et al. (2007) \\
\hline g) & ... successfully identify new business opportunities? & Zhao et al. (2005) \\
\hline h) & ... create new products? & Zhao et al. (2005) \\
\hline i) & ... think creatively? & Zhao et al. (2005) \\
\hline j) & ... commercialize an idea or new development? & Zhao et al. (2005) \\
\hline k) & ... raise funds for a new business? & Monsen (pers. comm.) \\
\hline 1) & ... sell a new product or service? & Monsen (pers. comm.) \\
\hline
\end{tabular}

The format follows the format by Wilson et al. (2007). Zhao et al. (2005) do not ask for a comparative judgment but for an absolute judgment of own ability. Since other studies revealed that comparative judgments might be more appropriate, we utilized the comparative format. 


\section{Appendix B.}

\section{Dictator treatments}

\begin{tabular}{|c|c|}
\hline Name & Description \\
\hline $\begin{array}{l}\text { T1 } \\
\text { Euro Gain }\end{array}$ & $\begin{array}{l}\text { You gain EUR } 10 \text { and the passive player gains EUR } 0 \text { (on top of your respective initial budgets). You } \\
\text { can either leave earnings unchanged, or decrease your own, increasing the passive player's earnings. If } \\
\text { you decrease your own earnings, this increases the passive player's earnings by the same amount. } \\
\text { What amount do you want to deduct from your earnings and add to the earnings of the passive player? }\end{array}$ \\
\hline $\begin{array}{l}\text { INTRO: } \\
\text { T2-T6 }\end{array}$ & $\begin{array}{l}\text { In this part there will be two lottery boxes. Each of the two boxes contains } 100 \text { lottery tickets. One box } \\
\text { is yours (active player) and determines your earnings by drawing one ticket at random. The other box } \\
\text { belongs to the passive player and determines his/her earnings in the same way. At the end of each } \\
\text { decision round, exactly one lottery ticket will be randomly drawn out of each of the two boxes. } \\
\text { There are three different kinds of lottery tickets that play a role in these five decision rounds: } \\
\text { - GREEN tickets, if drawn, increase the earnings of the owner of the box by EUR } 10 \text {. } \\
\text { - RED tickets, if drawn, decrease the earnings of the owner of the box by EUR } 10 \text {. } \\
\text { - WHITE tickets, if drawn, leave the earnings of the owner of the box unchanged. }\end{array}$ \\
\hline $\begin{array}{l}\text { T2 } \\
\text { Gain } \\
\text { Lottery }\end{array}$ & $\begin{array}{l}\text { You have } 100 \text { GREEN tickets (worth EUR 10) and the passive player has } 100 \text { WHITE tickets (worth } \\
\text { EUR 0). You can exchange some or all of your GREEN tickets in your box with some or all of the } \\
\text { WHITE tickets of the passive player's box, or you can leave the distribution of tickets unchanged. For } \\
\text { every GREEN ticket you exchange, you receive one WHITE ticket of the passive player. } \\
\text { How many GREEN tickets do you want to exchange for WHITE tickets of the passive player? }\end{array}$ \\
\hline $\begin{array}{l}\text { T3 } \\
\text { Loss } \\
\text { Lottery }\end{array}$ & $\begin{array}{l}\text { You have } 100 \text { RED tickets (worth EUR -10) and the passive player has } 100 \text { WHITE tickets (worth } \\
\text { EUR 0). You can exchange some or all of your RED tickets in your box with some or all of the } \\
\text { WHITE tickets of the passive player's box, or you can leave the distribution of tickets unchanged. For } \\
\text { every RED ticket you exchange, you receive one WHITE ticket of the passive player. } \\
\text { How many RED tickets do you want to exchange for WHITE tickets of the passive player? }\end{array}$ \\
\hline $\begin{array}{l}\text { INTRO: } \\
\text { T4-T6 }\end{array}$ & $\begin{array}{l}\text { In this part the } 100 \text { tickets in each of the two lottery boxes are WHITE (EUR } 0 \text { ). In each of the three } \\
\text { treatments, you, the active player, will be asked to convert some of the tickets into another color. } \\
\text { Which tickets you can convert in which of the boxes, how many tickets, and into which color, depends } \\
\text { on the specific decision round. } \\
\text { Each conversion from a WHITE into a GREEN ticket in your own box (active player) automatically } \\
\text { converts one WHITE ticket into a RED ticket in the passive player's box. Such a conversion therefore } \\
\text { increases your chances to get a GREEN ticket, but also increases the passive player's chances to get a } \\
\text { RED ticket. }\end{array}$ \\
\hline $\begin{array}{l}\mathrm{T} 4 \\
\text { Externality }\end{array}$ & $\begin{array}{l}\text { For every ticket converted from WHITE into GREEN (EUR } 10 \text { gain) in your box, a WHITE ticket } \\
\text { (EUR 0) in the passive player's box will automatically be converted into RED (EUR } 10 \text { loss). You can } \\
\text { convert up to } 100 \text { WHITE tickets to GREEN tickets, but only in your box. } \\
\text { How many WHITE tickets do you want to convert into GREEN tickets in your box, implying the same } \\
\text { number of WHITE tickets is converted into RED tickets in the passive player's box? }\end{array}$ \\
\hline $\begin{array}{l}\text { T5 } \\
\text { Externality } \\
\text { Recovery }\end{array}$ & $\begin{array}{l}\text { For every ticket converted from WHITE into GREEN (EUR } 10 \text { gain) in your box, a WHITE ticket } \\
\text { (EUR 0) in the passive player's box will automatically be converted into RED (EUR } 10 \text { loss). You can } \\
\text { convert up to } 100 \text { WHITE tickets to GREEN tickets. Unused ticket conversions that you do not use to } \\
\text { convert WHITE into GREEN in your box, are used to convert the RED tickets in the passive player's } \\
\text { box back into WHITE tickets. } \\
\text { How many WHITE tickets do you want to convert into GREEN tickets in your box, implying the same } \\
\text { number of WHITE tickets is converted into RED tickets in the passive player's box? }\end{array}$ \\
\hline $\begin{array}{l}\text { T6 } \\
\text { Externality } \\
\text { Positive }\end{array}$ & $\begin{array}{l}\text { For every ticket converted from WHITE into GREEN (EUR } 10 \text { gain) in your box, a WHITE ticket } \\
\text { (EUR 0) in the passive player's box will automatically be converted into RED (EUR } 10 \text { loss). You can } \\
\text { convert up to } 100 \text { WHITE tickets to GREEN tickets. Those unused tickets that you do not use to } \\
\text { convert WHITE into GREEN in your box, are used to convert the RED tickets in the passive player's } \\
\text { box back into WHITE tickets. If there are conversions left after converting passive player's RED } \\
\text { tickets into WHITE, these will be used to convert passive player's WHITE tickets into GREEN. } \\
\text { How many WHITE tickets do you want to convert into GREEN tickets in your box, implying the same } \\
\text { number of WHITE tickets is converted into RED tickets in the passive player's box? }\end{array}$ \\
\hline
\end{tabular}




\section{APPENDIX C \\ Decision screens for Treatments T5 and T6}

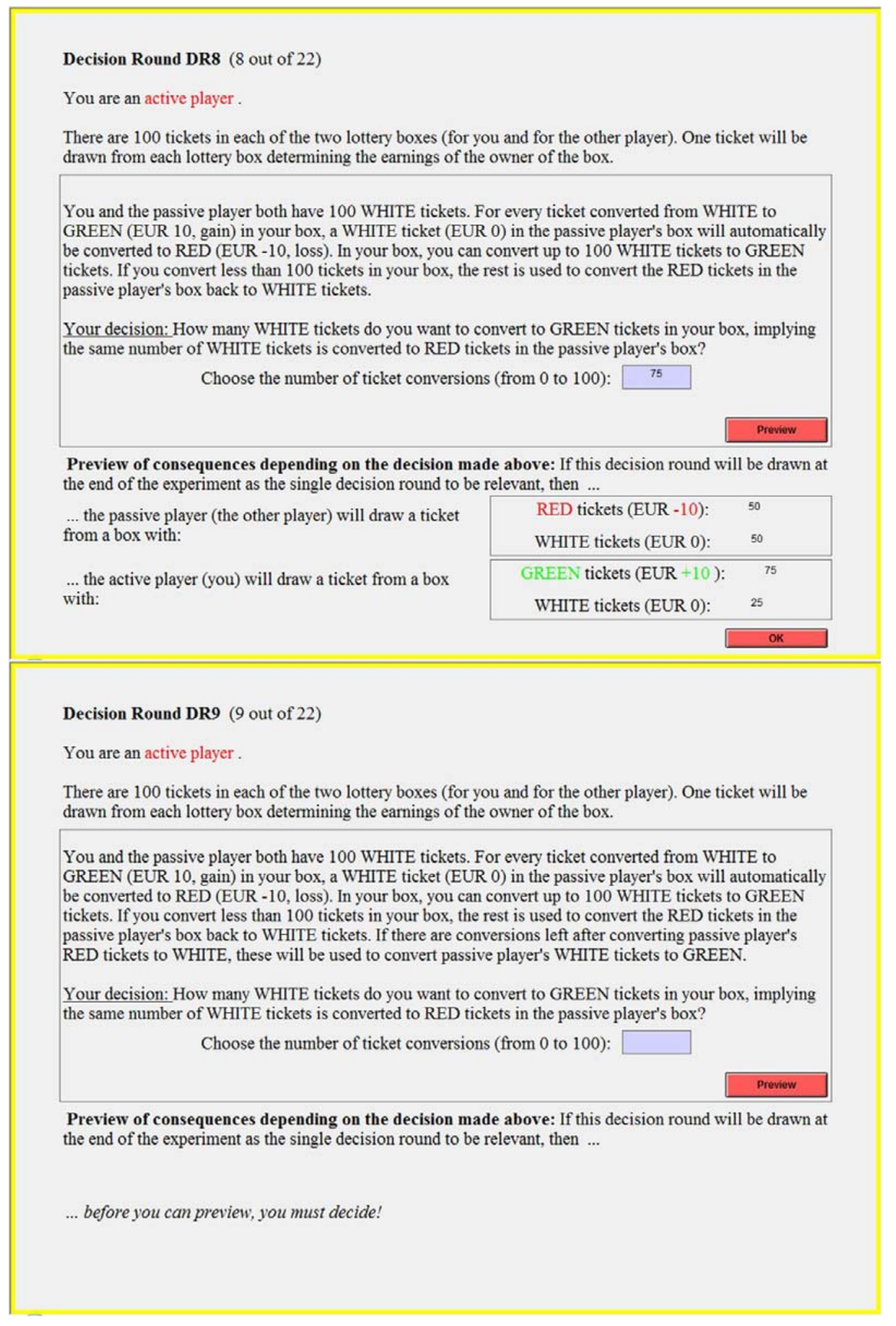


TABLE 1

Pearson correlations of psychometric variables and cumulative response (assumed to be metric)

\begin{tabular}{llllllllllll}
\hline \hline & 1 & 2 & 3 & 4 & 5 & 6 & 7 & 8 & 9 & 10 \\
\hline 1 & Creativity & 1 & & & & & & & & & \\
2 & Business talent & -.01 & 1 & & & & & & & & \\
3 & Social dominance & -.11 & .15 & 1 & & & & & & & \\
4 & Social responsibility & $.27^{*}$ & .15 & $-.25^{+}$ & 1 & & & & & & \\
5 & Extraversion & $.28^{*}$ & $.33^{*}$ & -.01 & $.49^{* * *}$ & & & & & & \\
6 & Agreeableness & -.21 & -.07 & -.15 & .10 & .04 & 1 & & & & \\
7 & Conscientiousness & .14 & .10 & .07 & .20 & .10 & .04 & 1 & & & \\
8 & Neuroticism & -.01 & $-.28^{*}$ & $.24^{+}$ & -.01 & -.17 & -.15 & .11 & 1 & & \\
9 & Openness & $.65^{* * *}$ & -.14 & -.07 & .19 & $.29^{*}$ & -.11 & .13 & -.08 & 1 & \\
10 & Cumulated response & $-.25^{*}$ & $.22^{+}$ & .12 & -.21 & -.04 & -.07 & -.03 & $-.24^{+}$ & -.03 & 1 \\
\hline \hline
\end{tabular}

$\mathrm{N}=60$. Significance levels $\mathrm{p}<0.10(+), \mathrm{p}<0.05(*), \mathrm{p}<0.01(* *), \mathrm{p}<0.005(* * *)$.

TABLE 2

Rank-based correlation coefficients for business talent and creativity with cumulated response and all treatment responses

\begin{tabular}{|c|c|c|c|c|c|c|c|}
\hline & Mean & Std. & Median & \multicolumn{2}{|c|}{ Spearman's $\tau$} & \multicolumn{2}{|c|}{ Kendall's tau } \\
\hline & & & & BT & $\mathrm{C}$ & BT & $\mathrm{C}$ \\
\hline CR & 0.000 & 5.214 & 2.211 & $.23^{+}$ & $-.24^{+}$ & .14 & $-.16^{+}$ \\
\hline Т 1 & 8.225 & 2.072 & 10 & $.25^{+}$ & $-.25^{+}$ & $.15^{+}$ & $-.16^{+}$ \\
\hline Т 2 & 8.878 & 2.006 & 10 & $.24^{+}$ & -.11 & $.14^{+}$ & -.07 \\
\hline Т 3 & 8.578 & 2.099 & 10 & .19 & $-.25^{+}$ & .11 & $-.16^{+}$ \\
\hline Т 4 & 7.245 & 3.377 & 9.5 & $.33^{*}$ & -.17 & $.20^{*}$ & -.11 \\
\hline Т 5 & 8.017 & 2.366 & 9.25 & $.23^{+}$ & -.18 & .14 & -.11 \\
\hline Т 6 & 7.723 & 2.843 & 9 & .14 & -.20 & .08 & -.13 \\
\hline
\end{tabular}

$\mathrm{N}=60$. Significance levels $\mathrm{p}<0.10(+), \mathrm{p}<0.05(*), \mathrm{p}<0.01(* *), \mathrm{p}<0.005(* * *)$. 
TABLE 3

Nonparametric tests whether business-talented uncreative participants stand out from the rest of the population with respect to their decisions

\begin{tabular}{|c|c|c|c|c|c|c|c|}
\hline & CR & T1 & T2 & T3 & T4 & $\mathbf{T 5}$ & T6 \\
\hline \multicolumn{8}{|c|}{$\overline{\text { Mann-Withney tests (z value) }}$} \\
\hline $\mathrm{BT}+/ \mathrm{C}-$ vs. rest & $-3.03^{* * *}$ & $-2.47^{*}$ & $-2.59^{* *}$ & $-2.79^{* *}$ & $-3.41^{* * *}$ & $-2.65^{* *}$ & $-2.48^{*}$ \\
\hline $\mathrm{BT}+/ \mathrm{C}-$ vs. $\mathrm{BT}+/ \mathrm{C}+$ & $-2.84^{* * *}$ & $-2.11^{*}$ & $-2.39^{*}$ & $-2.76^{* *}$ & $-3.20^{* * *}$ & $-2.57^{*}$ & $-2.49^{*}$ \\
\hline $\mathrm{BT}+/ \mathrm{C}-$ vs. BT-/C- & $-2.70^{* *}$ & $-2.16^{*}$ & $-2.48^{*}$ & $-2.47^{*}$ & $-3.16^{* * *}$ & $-2.58^{* *}$ & $-2.10^{*}$ \\
\hline \multicolumn{7}{|c|}{ Kruskal-Wallis test $\left(\chi^{2}\right)$} & $-1.65^{+}$ \\
\hline Rest equal & .373 & .109 & .478 & .603 & .233 & .776 & .445 \\
\hline All equal & $9.65^{*}$ & 6.17 & $7.20^{+}$ & $8.37^{*}$ & $11.77^{* *}$ & $8.02^{*}$ & $6.68^{+}$ \\
\hline \multicolumn{8}{|c|}{ Add. Mann-Withney tests (z value) } \\
\hline $\mathrm{BT}-/ \mathrm{C}+$ vs. $\mathrm{BT}-/ \mathrm{C}-$ & -.305 & -.273 & -.617 & -.022 & -.227 & -.689 & -.167 \\
\hline $\mathrm{BT}-/ \mathrm{C}+$ vs. $\mathrm{BT}+/ \mathrm{C}-$ & -.565 & -.305 & -.592 & -.679 & .100 & -.832 & -.698 \\
\hline
\end{tabular}

Significance levels $\mathrm{p}<0.10(+), \mathrm{p}<0.05(*), \mathrm{p}<0.01(* *), \mathrm{p}<0.005(* * *)$.

TABLE 4

Ordered probit regression analysis for business talent and creativity on egoism and a nonparametric test for uncreative business-talented people for all treatments and the average response

\begin{tabular}{|c|c|c|c|c|c|c|c|}
\hline & 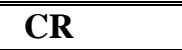 & T1 & $\overline{T 2}$ & $\overline{~ T 3}$ & T4 & T55 & T6 \\
\hline Age & $-.078(.144)$ & $-.086(.171)$ & $-.213(.169)$ & $-.103(.194)$ & $-.084(.177)$ & $.076(.140)$ & $.034(.152)$ \\
\hline Gender & $-.109(.165)$ & $-.166(.161)$ & $.015(.182)$ & $-.053(.177)$ & $.022(.169)$ & $-.227(.160)$ & $-.105(.163)$ \\
\hline Jena & $.297(.137)^{*}$ & $.303(.178)^{+}$ & $.251(.151)^{+}$ & $.443(.174)^{*}$ & $.275(.160)^{+}$ & $.280(.143)^{+}$ & $.198(.140)$ \\
\hline BT & $.224(.125)^{+}$ & $.258(.209)$ & $.307(.156)^{*}$ & $.351(.161)^{*}$ & $.532(.151)^{* * *}$ & $.233(.126)^{+}$ & $.087(.131)$ \\
\hline C & $-.390(.162)^{*}$ & $-.533(.213)^{*}$ & $-.175(.183)$ & $-.686(.256)^{* *}$ & $-.439(.169)^{*}$ & $-.343(.158)^{*}$ & $-.399(.186)^{*}$ \\
\hline BT $x$ C & $-.387(.168)^{*}$ & $-.463(.200)^{*}$ & $-.498(.191)^{* *}$ & $-.670(.239)^{* *}$ & $-.585(.167)^{* * *}$ & $-.308(.181)^{+}$ & $-.421(.216)^{+}$ \\
\hline Pseudo $\mathrm{R}^{2}$ & .0496 & .1008 & .0733 & .1320 & .0991 & .0626 & .0580 \\
\hline
\end{tabular}


TABLE 5

Ordered probit regression analysis for business talent and creativity on egoism and nonparametric test for uncreative business-talented people for all treatments and the average response

\begin{tabular}{|c|c|c|c|c|c|c|c|c|}
\hline Cum. Resp. & $\mathbf{I}$ & II & III & IV & $\mathbf{V}$ & VI & VII & VIII \\
\hline Age & $-.10(.15)$ & $-.08(.14)$ & $-.06(.14)$ & $-.07(.14)$ & $-.07(.15)$ & $-.09(.15)$ & $-.04(.15)$ & $-.13(.15)$ \\
\hline Gender & $-.08(.17)$ & $-.11(.17)$ & $-.09(.16)$ & $-.01(.17)$ & $.04(.18)$ & $.11(.18)$ & $-.06(.17)$ & $.17(.17)$ \\
\hline Jena & $.29(.14)^{*}$ & $.30(.14)^{*}$ & $.30(.14)^{*}$ & $.35(.14)^{*}$ & $.41(.16)^{*}$ & $.43(.17)^{*}$ & $.32(.15)^{*}$ & $.44(.19)^{*}$ \\
\hline SocDom & & & $.13(.20)$ & $-.08(.20)$ & $.17(.19)$ & $.22(.19)$ & $.03(.19)$ & $.30(.19)$ \\
\hline SocRes & & & & $-.32(.15)^{*}$ & $-.31(.15)^{*}$ & $-.33(.16)^{*}$ & $-.31(.15)^{*}$ & $-.36(.17)^{*}$ \\
\hline Extraversion & & & & & $-.08(.15)$ & $-.02(.15)$ & $-.06(.16)$ & $-.07(.16)$ \\
\hline Agreeableness & & & & & $-.10(.19)$ & $-.09(.20)$ & $-.05(.17)$ & $.02(.21)$ \\
\hline Conscientiousnes & & & & & $.12(.15)$ & $.14(.14)$ & $.04(.15)$ & $.16(.13)$ \\
\hline Neurotiscism & & & & & $-.47(.23)^{*}$ & $-.51(.24)^{*}$ & & $-.57(.22)^{* *}$ \\
\hline Openness & & & & & $.36(.20)^{+}$ & & $.44(.20)^{*}$ & $-.03(.13)$ \\
\hline BT & $.24(.12)^{*}$ & $.22(.13)^{+}$ & $.22(.12)^{+}$ & $.29(.13)^{*}$ & $.23(.17)$ & $.15(.16)$ & $.27(.15)^{+}$ & \\
\hline C & $-.35(.17)^{*}$ & $-.39(.16)^{*}$ & $-.39(.16)^{*}$ & $-.33(.16)^{*}$ & $-.60(.21)^{* *}$ & $-.36(.16)^{*}$ & $-.26(.21)$ & \\
\hline BT x C & & $-.39(.17)^{*}$ & $-.37(.16)^{*}$ & $-.37(.18)^{*}$ & $-.37(.17)^{*}$ & $-.37(.18)^{*}$ & $-.36(.18)^{*}$ & \\
\hline Pseudo $\mathrm{R}^{2}$ & .0325 & .0496 & .0515 & .0617 & .0941 & .0854 & .0758 & .0571 \\
\hline
\end{tabular}




\section{FIGURE 1}

\section{Business Talent Versus Creativity for Standardized Values}

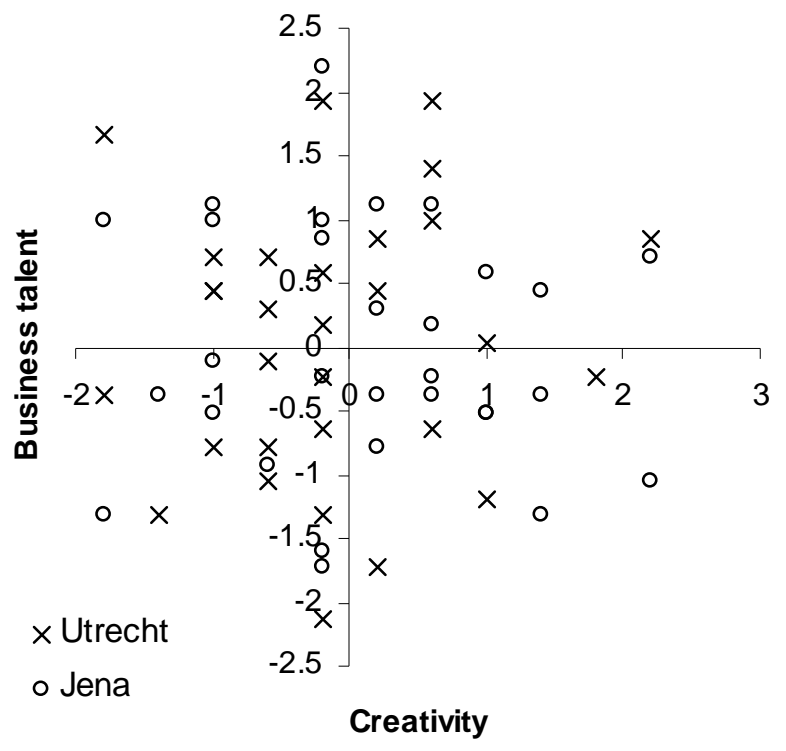

\section{FIGURE 2}

Interaction of Business Talent and Creativity for Cumulated Response

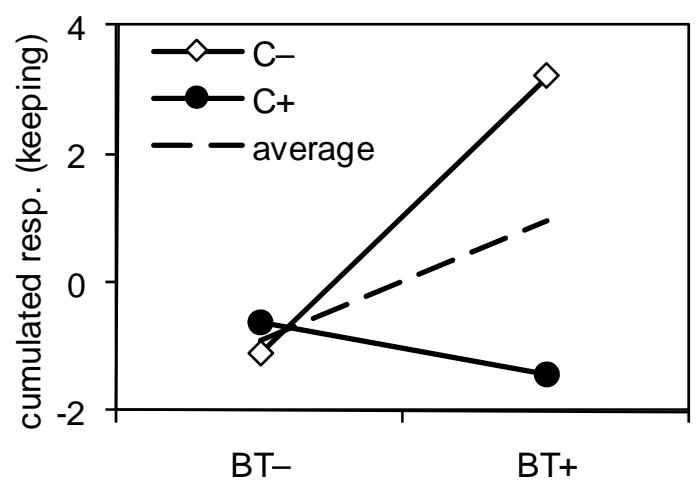




\section{FIGURE 3}

Interaction of Business Talent and Creativity for All Treatments
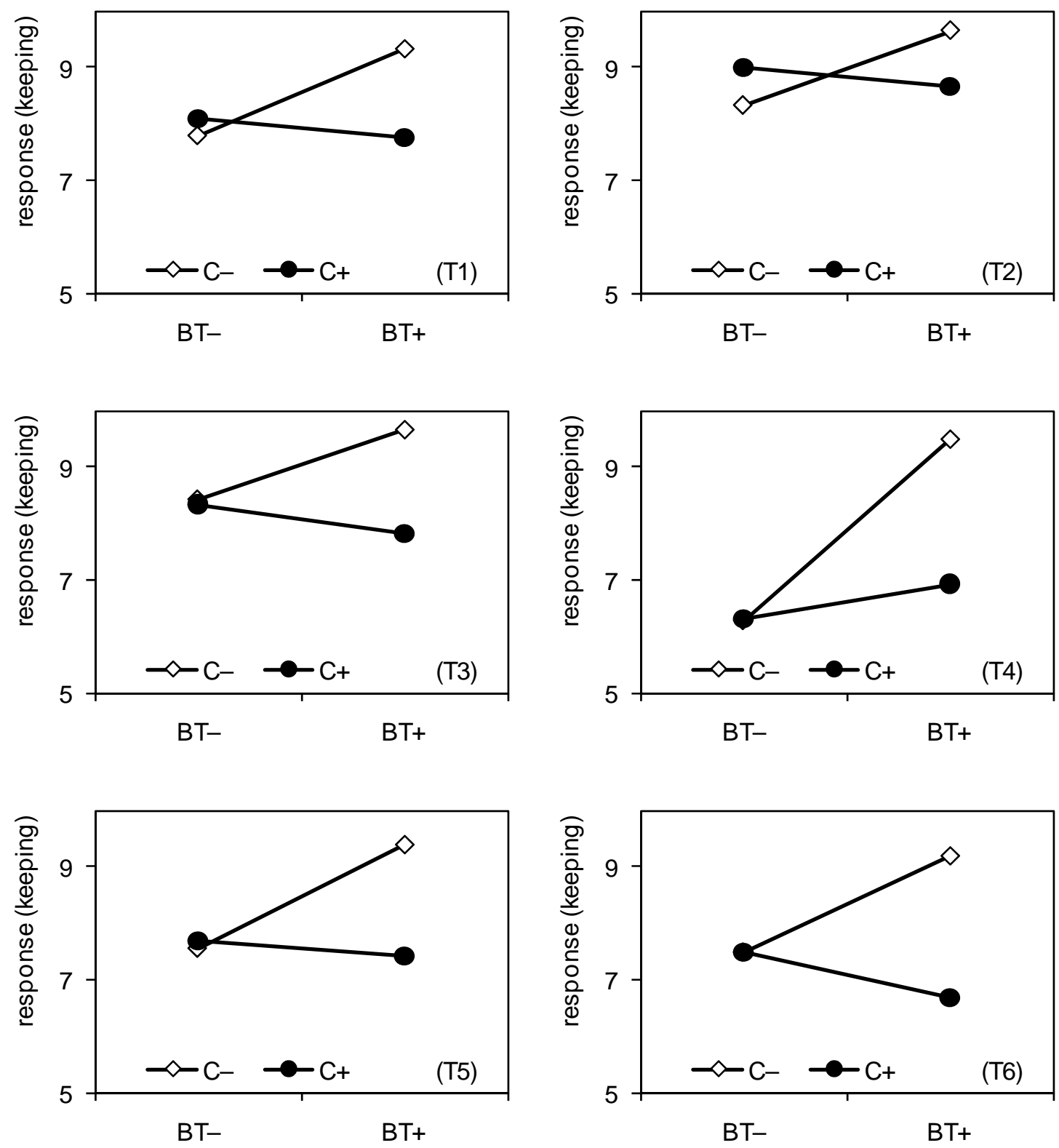